\title{
Association between blood pressure and disability-free survival among community-dwelling elderly patients receiving antihypertensive treatment
}

\author{
Osamu Iritani ${ }^{1}$, Yumi Koizumi ${ }^{2}$, Yuko Hamazaki ${ }^{2}$, Hiroshi Yano ${ }^{1}$, Takuro Morita ${ }^{1}$, Taroh Himeno ${ }^{1}$, \\ Tazuo Okuno ${ }^{1}$, Masashi Okuro ${ }^{1}$, Kunimitsu Iwai ${ }^{1}$ and Shigeto Morimoto ${ }^{1}$
}

A reduction of elevated blood pressure (BP) is an important treatment goal in elderly hypertensive patients. However, excessive reduction of systolic BP (SBP) and/or diastolic BP (DBP) might be harmful in such patients. We investigated whether this was the case with regard to risk of incident disability or death in community-dwelling elderly subjects. We analyzed 570 patients receiving antihypertensive treatment aged 65-94 years. The endpoint was the composite outcome of incident disability, defined as first certification of a support/care need or death. Relationships among each of the four classes of SBP or DBP and the risk of incident disability or death were estimated using the Cox proportional hazards model. Over four years, 77 (13.5\%) incident disabilities or deaths occurred. After adjustment for age, sex and variables selected according to their univariate analysis $P$-value $<0.20$, the risk of events was significantly higher in subjects with baseline $\mathrm{SBP}<120 \mathrm{~mm} \mathrm{Hg}$ (hazard ratio $(\mathrm{HR})=2.81, P=0.023)$ and $\geqslant 160 \mathrm{~mm} \mathrm{Hg}(\mathrm{HR}=4.32, P<0.001)$, compared with subjects with baseline SBP of $140-159 \mathrm{~mm} \mathrm{Hg}$, who showed the lowest incidence of events. This J-curve relationship was observed in very elderly patients ( $\geqslant 75$ years) but not in younger patients. Patients with $\mathrm{SBP}<120 \mathrm{~mm} \mathrm{Hg}$ tended to have a higher risk of incident disability caused by cerebral events, and those with $\mathrm{SBP} \geqslant 160 \mathrm{~mm} \mathrm{Hg}$ had a higher risk of incident disability caused by falls/bone fractures. These observations indicate that excessive BP reduction could cause discontinuance of disability-free survival in community-dwelling elderly patients.

Hypertension Research (2014) 37, 772-778; doi:10.1038/hr.2014.67; published online 27 March 2014

Keywords: disability; elderly; J-curve; treatment

\section{INTRODUCTION}

Providing high-quality treatment to older adults with elevated blood pressure (BP), which is aimed at both the prevention of cardiovascular/cerebrovascular (CV) morbidity/mortality and the promotion of cognitive/physical function, is growing in importance because of the improved survival of patients with hypertension into old age. Many large-scale intervention trials, including a meta-analysis of eight large-scale intervention trials in elderly hypertensive patients aged $\geqslant 60$ years, ${ }^{1}$ recent clinical trials limited to elderly patients aged $\geqslant 60$ years,$~^{2-7}$ and Hypertension in the Very Elderly Trial, ${ }^{8}$ which enrolled those aged $\geqslant 80$ years, have revealed significant reductions in CV morbidity/mortality with antihypertensive treatment. By contrast, several long-term interventional trials also have demonstrated J-curve phenomena for the relationships of achieved systolic BP (SBP), ${ }^{3,9-11}$ diastolic BP (DBP) ${ }^{12,13}$ and both ${ }^{14}$ with CV morbidity/ mortality in elderly hypertensive patients with various $\mathrm{CV}$ conditions, including coronary heart disease. Moreover, hypertension is also known to be linked to frailty in the elderly. ${ }^{15,16}$ In Japan, the public Long-Term Care Insurance system provides services to disabled older adults who have been certified as requiring support (levels 1-2) or care (levels 1-5). ${ }^{17,18}$ However, few studies have examined the association of BP with disability-free survival in community-dwelling elderly hypertensive patients. Therefore, we sought to determine the appropriate BP for elderly patients receiving antihypertensive treatment by examining the associations between baseline BP and the risk of incident disability or death.

\section{METHODS}

Subjects

The target area was a town with a population of $\sim 30000$ in Ishikawa, Japan. The proportion of elderly people aged $\geqslant 65$ years in the total population was $19.6 \%$ (2010). The local government provides a public health center-based annual health check-up to these elderly subjects. In April 2008, of all 4050 community-dwelling uncertified elderly subjects aged $\geqslant 65$ years, 1091 supplied complete information at the time of their health check-ups. Of those subjects, $62.6 \%$ were hypertensive, defined as $\mathrm{BP} \geqslant 140 / 90 \mathrm{~mm} \mathrm{Hg}$ or receiving current antihypertensive treatment $(n=683)$. Among hypertensive subjects, 
$84.8 \%$ were receiving antihypertensive treatment $(n=579)^{19}$ and were included in our study.

\section{Baseline examinations}

A self-administered questionnaire, which included medical history and time since the last meal, ${ }^{20}$ was completed at baseline. The blood condition was defined as fasting if blood was collected more than $8 \mathrm{~h}$ after the last meal. Chronic kidney disease was defined as an estimated glomerular filtration rate, calculated using the modification of diet in renal disease equation with coefficients modified for Japanese patients, ${ }^{21}$ of $<60 \mathrm{ml} \mathrm{min}^{-1} 1.73 \mathrm{~m}^{-2}$. Diabetes mellitus was defined as fasting blood glucose $\geqslant 7.0 \mathrm{mmoll}^{-1}$ $\left(126 \mathrm{mg} \mathrm{dl}^{-1}\right)$, non-fasting glucose $\geqslant 11.1 \mathrm{mmoll}^{-1}\left(200 \mathrm{mg} \mathrm{dl}^{-1}\right)$, HbAlc $\geqslant 6.5 \%$ by a standardized method, or the use of hypoglycemic agents and/or insulin. ${ }^{22}$ Dyslipidemia was defined as fasting serum total cholesterol $\geqslant 220 \mathrm{mg} \mathrm{dl}^{-1}$, triglycerides $\geqslant 150 \mathrm{mg} \mathrm{dl}^{-1}$, HDL cholesterol $<40 \mathrm{mg} \mathrm{dl}^{-1}$, or use of the lipid-lowering agents. ${ }^{23}$ Hyperuricemia was defined as serum uric acid $\geqslant 7.0 \mathrm{mg} \mathrm{dl}^{-1}$ in men and $\geqslant 6.0 \mathrm{mg} \mathrm{dl}^{-1}$ in women or the use of uric acid-lowering agents. ${ }^{24}$ Hypoalbuminemia was defined as serum albumin $<4 \mathrm{~g} \mathrm{dl}^{-1} .25$

Measurements of baseline BP were performed based on the guidelines for the management of hypertension, ${ }^{26}$ by trained observers using a mercury sphygmomanometer.

\section{Analysis}

The primary endpoint of the present study was the composite outcome of incident disability, defined as the first certification for any level of support/care need, or death. Support/care need was judged by the Regional Comprehensive Support Center (RCSC) of the local government, on the basis of the investigation form completed by interview by the RCSC staff and of the doctor's assessment form completed by the physician in charge. ${ }^{17} \mathrm{We}$ also examined the first disease causing the need for support/care need on the papers of all certificated persons, and we classified the diseases into four categories, namely cerebral events, falls/bone fractures, dementia/depression and other diseases. Baseline SBP and DBP were each classified into four classes (SBP: $<120,120-139,140-159$ and $\geqslant 160 \mathrm{~mm} \mathrm{Hg}$; DBP: $<70,70-79,80-89$ and $\geqslant 90 \mathrm{~mm} \mathrm{Hg}$ ). 3,9 The results for continuous variables in baseline clinical characteristics were compared using Mann-Whitney $U$-analysis. Discrete variables were compared by $\chi^{2}$-analysis. Comparisons of data among the groups of SBP and DBP were performed by the Kruskal-Wallis test with Bonferroni's correction. Proportional hazards regression (Cox) models ${ }^{27}$ were used to estimate the unadjusted hazard ratio (HR) of incident disability or death with $95 \%$ confidence intervals (CIs) by age, sex, risk factors shown in Table 1, and classes of SBP or DBP. Multivariate models were used to adjust for potential confounding factors at $P<0.20 .{ }^{28}$ Using Cox regression, the HR for each baseline BP (SBP: 140-159 mm Hg; DBP: 70-79 $\mathrm{mm} \mathrm{Hg}$ ) and the corresponding 95\% CI were calculated. Data were analyzed using IBM-SPSS software (v. 18.0, IBM-SPSS, Chicago, IL, USA).

\section{Ethical considerations}

The study was formally approved by the Clinical Research Ethics Committee of Kanazawa Medical University. It was also approved by official agreement between the mayor of the town and us. We received baseline data and information of new onset of disability or death, which were irreversibly anonymized, during the follow-up period from the RCSC of the town.

\section{RESULTS}

\section{Study population}

Out of the 579 treated hypertensive elderly patients, nine moved out of the area during the four-year period and were also excluded. A total of 570 subjects ( 225 men and 345 women) were included in this analysis. Table 1 shows the baseline clinical characteristics of all of the patients at study entry. The mean \pm s.d. age of subjects was $74.2 \pm 6.1$ years (65-94 years). The percentage of patients aged $\geqslant 75$ years was $46.3 \%$ (Table 1).

\section{Disability and death}

A total of 77 subjects $(33.8 / 1,000$ person-years) either became disabled or died. These patients included 62 cases of incident disability (27.2/1,000 person-years) and 15 deaths without disability (6.6/1,000 person-years). Seven patients died after incident disability (3.1/1,000 person-years), and a total of 22 died (9.6/1,000 personyears) during the period (Table 1). Compared with patients with disability-free survival, patients with incident disability or death showed a significantly higher mean age and higher female sex rate (Table 1). The incidence rates of the composite outcome of incident disability and death for patients with baseline SBP $<120,120-139$, 140-159 and $\geqslant 160 \mathrm{~mm} \mathrm{Hg}$ were 45.9, 34.7, 19.7 and 75.6/1,000 person-years, respectively, while those for patients with baseline $\mathrm{DBP}<70,70-79,80-89$ and $\geqslant 90 \mathrm{~mm} \mathrm{Hg}$ were $37.5,33.3,33.3$ and 32.9/1,000 person-years, respectively. The Kruskal-Wallis test revealed higher incidences of a past history of heart disease in the lower SBP groups and higher incidences of past histories of stoke, chronic kidney disease and diabetes mellitus in the lower DBP groups (Table 2).

Age, female sex, past history of stroke, past history of heart disease, chronic kidney disease, diabetes mellitus, hyperuricemia, and hypoalbuminemia were associated with the risk of incident disability or death in univariate analyses and were sequentially included in the final Cox proportional hazards regression model. The relationship between baseline SBP or DBP and the incidence of events is shown in Figure 1. After adjustment for these factors, the HR for disability or death over four years was significantly higher in subjects with baseline $\mathrm{SBP}<120 \mathrm{~mm} \mathrm{Hg}(\mathrm{HR}=2.81,95 \% \mathrm{CI}=1.15-6.82, P=0.023)$ and $\geqslant 160 \mathrm{~mm} \mathrm{Hg}(\mathrm{HR}=4.32,95 \% \mathrm{CI}=1.90-9.83, P<0.001)$, compared with subjects with baseline SBP of 140-159 $\mathrm{mm} \mathrm{Hg}$, which yielded the lowest incidence of events (Figure 1). After adjustment for the same factors, the HR for disability alone was also significantly higher both in subjects with baseline $\mathrm{SBP}<120 \mathrm{~mm} \mathrm{Hg}$ ( $\mathrm{HR}=3.37,95 \%$ $\mathrm{CI}=1.18-9.60, P=0.023)$ and in those with baseline $\mathrm{SBP} \geqslant 160 \mathrm{~mm}$ $\mathrm{Hg}(\mathrm{HR}=4.09,95 \% \mathrm{CI}=1.03-8.16, P=0.043)$, compared with control subjects (Figure 1). Compared with the same control group, the HR for all-cause death was significantly higher in those with baseline $\quad \mathrm{SBP} \geqslant 160 \mathrm{~mm} \mathrm{Hg} \quad(\mathrm{HR}=6.10, \quad 95 \% \quad \mathrm{CI}=1.33-19.5$, $P=0.017)$ but not in those with $<120 \mathrm{mmHg}$. There was no difference in HR among each of the baseline DBP classes (Figure 1).

In the subgroup of patients aged $\geqslant 75$ years, subjects with baseline $\mathrm{SBP}<120 \mathrm{~mm} \mathrm{Hg}$ or $\geqslant 160 \mathrm{~mm} \mathrm{Hg}$ had a significantly higher risk of all events $(\mathrm{SBP}<120 \mathrm{~mm} \mathrm{Hg}: \mathrm{HR}=3.30, \quad 95 \% \quad \mathrm{CI}=1.18-9.21$, $P=0.023 ; \quad \mathrm{SBP} \geqslant 160 \mathrm{mmHg}: \quad \mathrm{HR}=4.41, \quad 95 \% \quad \mathrm{CI}=1.62-12.0$, $P=0.004$ ) (Figure 2) and of incident disability alone (SBP $<120 \mathrm{~mm} \mathrm{Hg}: \quad \mathrm{HR}=3.61, \quad 95 \% \quad \mathrm{CI}=1.12-12.0, \quad P=0.032 ; \quad \mathrm{SBP}$ $\geqslant 160 \mathrm{~mm} \mathrm{Hg}: \mathrm{HR}=3.67,95 \% \mathrm{CI}=1.20-11.2, P=0.022)$, compared with subjects with baseline SBP of $140-159 \mathrm{~mm} \mathrm{Hg}$. There were no differences in HRs in the subgroup of patients aged 65-74 years (Figure 2).

Among the 62 disabled subjects, 11 patients were disabled owing to cerebral events, 15 owing to falls/bone fractures, 17 owing to dementia/depression, and 19 owing to other diseases. Of the 11 patients disabled owing to cerebral events, $10 \mathrm{did}$ not have a previous history of stroke at the baseline examination. Conditional Cox hazard analysis revealed that the HR for disability owing to cerebral events was increased in subjects with baseline $<120 \mathrm{~mm} \mathrm{Hg}(\mathrm{HR}=27.3$, 95\% CI $=1.09-684, P=0.044$ ), while that for disability owing to falls/bone fractures was increased in patients with $\mathrm{SBP} \geqslant 160 \mathrm{~mm} \mathrm{Hg}$ $(\mathrm{HR}=25.0,95 \% \mathrm{CI}=1.61-388, P=0.021)$, compared with the control group (Figure 3 ). 
Table 1 Baseline characteristics of the total population with antihypertensive treatment

\begin{tabular}{|c|c|c|c|c|c|c|c|}
\hline & \multirow[b]{2}{*}{$\begin{array}{c}\text { Total, } \\
\mathrm{n}=570\end{array}$} & \multirow[b]{2}{*}{$\begin{array}{c}\text { Disability or } \\
\text { death, } \\
n=77\end{array}$} & \multirow[b]{2}{*}{$\begin{array}{c}\text { Disability, } \\
\mathrm{n}=62\end{array}$} & \multicolumn{3}{|c|}{ Death } & \multirow[b]{2}{*}{$\begin{array}{c}\text { Disability-free } \\
\text { survival, } \\
n=493\end{array}$} \\
\hline & & & & $\begin{array}{l}\text { Total, } \\
\mathrm{n}=22\end{array}$ & $\begin{array}{c}\text { Death with } \\
\text { disability, } \\
\mathrm{n}=7\end{array}$ & $\begin{array}{c}\text { Death without } \\
\text { disability, } \\
\mathrm{n}=15\end{array}$ & \\
\hline \multicolumn{8}{|l|}{ Demographics } \\
\hline Age (years) & $74.2 \pm 6.1$ & $79.5 \pm 5.6^{* * *}$ & $80.6 \pm 5.1^{* * *}$ & $78.1 \pm 6.9$ ** & $84.3 \pm 4.9^{* * *}$ & $75.1 \pm 5.7$ & $73.4 \pm 5.7$ \\
\hline Age > 75: $n(\%)$ & $264(46.3 \%)$ & $63(81.8 \%)^{* * *}$ & $55(88.7 \%)^{* * *}$ & $15(68.2 \%)^{\#}$ & $7(100 \%)^{* *}$ & $8(53.3 \%)$ & $201(40.8 \%)$ \\
\hline Females: $n(\%)$ & $345(60.5 \%)$ & $54(70.1 \%)^{\#}$ & $46(74.2 \%)^{*}$ & $10(45.5 \%)$ & $2(28.6 \%)$ & $8(53.3 \%)$ & $291(59.0 \%)$ \\
\hline $\mathrm{BMI}\left(\mathrm{kg} \mathrm{m}^{-2}\right)$ & $23.5 \pm 3.2$ & $23.5 \pm 3.9$ & $23.4 \pm 3.8$ & $23.0 \pm 4.3$ & $21.0 \pm 3.2^{\#}$ & $23.9 \pm 4.5$ & $23.5 \pm 3.1$ \\
\hline \multicolumn{8}{|l|}{ Complications } \\
\hline Past history of stroke: $n(\%)$ & $31(5.5 \%)$ & $8(10.5 \%)^{\#}$ & $4(6.5 \%)$ & $5(22.7 \%)^{* *}$ & $1(14.3 \%)$ & $4(26.7 \%)^{* *}$ & $23(4.7 \%)$ \\
\hline Past history of heart disease: $n(\%)$ & $100(17.9 \%)$ & $23(30.3 \%)^{* *}$ & $20(32.3 \%)^{* *}$ & $4(18.2 \%)$ & $1(14.3 \%)$ & $3(20.0 \%)$ & $77(15.6 \%)$ \\
\hline Chronic kidney disease: $n(\%)$ & $216(37.9 \%)$ & $37(48.1 \%)^{\#}$ & $33(53.2 \%)^{*}$ & $7(31.8 \%)$ & $3(42.9 \%)$ & $4(26.7 \%)$ & $179(36.3 \%)$ \\
\hline Diabetes mellitus: $n(\%)$ & $125(21.9 \%)$ & $23(29.9 \%)^{\#}$ & $22(35.5 \%)^{*}$ & $4(18.2 \%)$ & $3(42.9 \%)^{\#}$ & $1(6.7 \%)$ & $102(20.7 \%)$ \\
\hline Dyslipidemia: $n(\%)$ & $298(52.3 \%)$ & $43(55.8 \%)$ & $36(58.1 \%)$ & $11(50.0 \%)$ & $4(57.1 \%)$ & $7(46.7 \%)$ & $255(51.7 \%)$ \\
\hline Hyperuricemia: $n(\%)$ & $114(20.0 \%)$ & $17(22.1 \%)$ & $12(19.4 \%)$ & $7(31.8 \%)^{\#}$ & $2(28.6 \%)$ & $5(33.3 \%)^{\#}$ & $97(19.7 \%)$ \\
\hline Hypoalbuminemia: $n(\%)$ & $30(5.3 \%)$ & $12(15.6 \%)^{* * *}$ & $9(14.5 \%)^{* * *}$ & $7(31.8 \%)^{* * *}$ & $4(57.1 \%)^{* * *}$ & $3(20.0 \%)^{*}$ & $18(3.7 \%)$ \\
\hline \multicolumn{8}{|l|}{ Blood pressure at entry } \\
\hline Systolic (mm Hg) & $137.2 \pm 14.3$ & $139.3 \pm 16.4$ & $137.6 \pm 15.9$ & $141.7 \pm 16.7$ & $132.0 \pm 11.5$ & $146.2 \pm 17.1^{*}$ & $136.9 \pm 13.9$ \\
\hline$<120: n(\%)$ & $49(8.6 \%)$ & $9(11.7 \%)^{*}$ & $8(12.9 \%)^{*}$ & $2(9.1 \%)$ & $1(14.3 \%)$ & $1(6.7 \%)$ & $40(8.1 \%)$ \\
\hline 120-139: $n(\%)$ & $288(50.5 \%)$ & $40(50.5 \%)^{*}$ & $35(56.5 \%)^{*}$ & $10(45.5 \%)$ & $5(71.4 \%)$ & $5(33.3 \%)$ & $248(50.3 \%)$ \\
\hline 140-159: $n(\%)^{\mathrm{a}}$ & $190(33.3 \%)$ & $15(19.5 \%)$ & $11(17.7 \%)$ & $5(22.7 \%)$ & $1(14.3 \%)$ & $4(26.7 \%)$ & $175(35.5 \%)$ \\
\hline$\geqslant 160: n(\%)$ & $43(7.5 \%)$ & $13(16.9 \%)^{* * *}$ & $8(12.9 \%)^{* *}$ & $5(22.7 \%)^{* *}$ & $0(0.0 \%)$ & $5(33.3 \%)^{* *}$ & $30(6.1 \%)$ \\
\hline Diastolic (mmHg) & $78.4 \pm 9.0$ & $78.2 \pm 9.4$ & $77.3 \pm 9.3$ & $80.1 \pm 8.5$ & $76.0 \pm 6.2$ & $81.9 \pm 8.9$ & $78.4 \pm 9.0$ \\
\hline <70: $n(\%)$ & $80(14.0 \%)$ & $12(15.6 \%)$ & $11(17.7 \%)$ & $2(9.1 \%)$ & $1(14.3 \%)$ & $1(6.7 \%)$ & $68(13.8 \%)$ \\
\hline 70-79: $n(\%)^{\mathrm{b}}$ & $203(35.6 \%)$ & $27(35.1 \%)$ & $22(35.5 \%)$ & $8(36.4 \%)$ & $3(42.9 \%)$ & $5(33.3 \%)$ & $176(35.7 \%)$ \\
\hline 80-89: $n(\%)$ & $211(37.0 \%)$ & $28(36.4 \%)$ & $23(37.1 \%)$ & $8(36.4 \%)$ & $3(42.9 \%)$ & $5(33.3 \%)$ & $183(37.1 \%)$ \\
\hline$\geqslant 90: n(\%)$ & 76 (13.3\%) & $10(13.0 \%)$ & $6(9.7 \%)$ & $4(18.2 \%)$ & $0(0.0 \%)$ & $4(26.7 \%)$ & $66(13.4 \%)$ \\
\hline
\end{tabular}

Abbreviation: BMI, body mass index.

Results are expressed as mean \pm s.d., or $n(\%)$. Mann-Whitney $U$-analysis or $\chi^{2}$-analysis were used. ${ }^{\#} P<0.20,{ }^{*} P<0.05,{ }^{* *} P<0.01$ and ${ }^{* * *} P<0.001$ vs. group with disability-free survival. aReference SBP.

${ }^{\mathrm{b}}$ Reference DBP.

Table 2 Baseline characteristics by each quartile of SBP and DBP pressure.

\begin{tabular}{|c|c|c|c|c|c|c|c|c|c|c|}
\hline & \multicolumn{4}{|c|}{$S B P$} & \multirow{2}{*}{$\begin{array}{c}\text { Kruskal- } \\
\text { Wallis, } \\
\text { P-value }\end{array}$} & \multicolumn{4}{|c|}{$D B P$} & \multirow{2}{*}{$\begin{array}{c}\text { Kruskal- } \\
\text { Wallis, } \\
\text { P-value }\end{array}$} \\
\hline & $\begin{array}{l}<120 \\
\mathrm{n}=49\end{array}$ & $\begin{array}{c}120-139 \\
\mathrm{n}=288\end{array}$ & $\begin{array}{c}140-159 \\
\mathrm{n}=190^{\mathrm{a}}\end{array}$ & $\begin{array}{l}\geqslant 160, \\
n=43\end{array}$ & & $\begin{array}{c}<70 \\
\mathrm{n}=80\end{array}$ & $\begin{array}{c}70-79 \\
\mathrm{n}=203^{\mathrm{b}}\end{array}$ & $\begin{array}{l}80-89 \\
n=211\end{array}$ & $\begin{array}{l}\geqslant 90 \\
n=76\end{array}$ & \\
\hline \multicolumn{11}{|l|}{ Demographics } \\
\hline Age (years) & $73.3 \pm 5.6$ & $74.8 \pm 6.2^{*}$ & $73.4 \pm 5.7$ & $75.4 \pm 6.7^{\#}$ & * & $75.6 \pm 6.4$ & $74.8 \pm 6.3$ & $73.8 \pm 5.7^{\#}$ & $72.5 \pm 5.7^{* *}$ & * \\
\hline Age $>75$ years: $n(\%)$ & $23(46.9 \%)$ & $140(48.6 \%)^{\#}$ & $78(41.1 \%)$ & $23(53.5 \%)^{\#}$ & & $43(53.8 \%)$ & $100(49.3 \%)$ & $93(44.1 \%)$ & $28(36.8 \%)^{\#}$ & $\#$ \\
\hline Females: $n(\%)$ & $29(59.2 \%)^{\#}$ & $168(58.3 \%)^{\#}$ & $122(64.2 \%)$ & $26(60.5 \%)$ & & $48(60.0 \%)$ & $123(60.6 \%)$ & $130(61.6 \%)$ & $44(57.9 \%)$ & \\
\hline $\mathrm{BMI}\left(\mathrm{kg} \mathrm{m}^{-2}\right)$ & $23.9 \pm 2.7$ & $23.2 \pm 3.2^{\#}$ & $23.7 \pm 3.3$ & $24.0 \pm 3.3$ & \# & $23.3 \pm 3.6$ & $23.2 \pm 3.2$ & $23.8 \pm 3.0^{*}$ & $23.9 \pm 3.1^{\#}$ & $\#$ \\
\hline \multicolumn{11}{|l|}{ Complications } \\
\hline Past history of stroke: $n(\%)$ & $4(8.2 \%)$ & $17(5.9 \%)$ & $8(4.2 \%)$ & $2(4.7 \%)$ & & $2(2.5 \%)$ & $7(3.4 \%)$ & $19(9.0 \%)^{*}$ & $3(3.9 \%)$ & * \\
\hline Past history of heart disease: $n(\%)$ & $14(28.6 \%)^{*}$ & $58(20.1 \%)^{*}$ & $25(13.2 \%)$ & $3(7.0 \%)$ & ** & $22(27.5 \%)^{*}$ & $34(16.7 \%)$ & $33(15.6 \%)$ & $11(14.5 \%)$ & $\#$ \\
\hline Chronic kidney disease: $n(\%)$ & $23(45.9 \%)^{\#}$ & $117(40.6 \%)^{\#}$ & $61(32.1 \%)$ & $15(34.9 \%)$ & $\#$ & $41(51.3 \%)^{* *}$ & $70(34.5 \%)$ & $71(33.6 \%)$ & $34(44.7 \%)^{\#}$ & * \\
\hline Diabetes mellitus: $n(\%)$ & $10(20.4 \%)$ & $68(23.6 \%)$ & $39(20.5 \%)$ & $8(18.2 \%)$ & & $28(35.0 \%)^{*}$ & $49(24.1 \%)$ & $40(19.0 \%)$ & $8(10.5 \%)^{*}$ & ** \\
\hline Dyslipidemia: $n(\%)$ & $26(53.1 \%)$ & $151(52.4 \%)$ & $101(53.2 \%)$ & $20(46.5 \%)$ & & $43(53.8 \%)$ & $109(53.7 \%)$ & $106(50.2 \%)$ & $40(52.6 \%)$ & \\
\hline Hyperuricemia: $n(\%)$ & $8(16.3 \%)^{\#}$ & $33(11.5 \%)$ & $18(9.5 \%)$ & $9(20.9 \%)^{*}$ & $\#$ & 7 (8.8\%) & $26(12.8 \%)$ & $23(10.9 \%)$ & $12(15.8 \%)$ & \\
\hline Hypoalbuminemia: $n(\%)$ & $3(5.1 \%)$ & $17(5.9 \%)$ & 7 (3.7\%) & $3(7.9 \%)$ & & $8(10.0 \%)^{\#}$ & $9(4.4 \%)$ & $11(5.2 \%)$ & $2(2.6 \%)$ & $\#$ \\
\hline
\end{tabular}

Abbreviations: BMI, body mass index; DBP, diastolic blood pressure; SBP, systolic blood pressure.

Results are expressed as mean \pm s.d., or $n(\%)$. Mann-Whitney $U$-analysis or $\chi^{2}$-analysis was used.

Results are expresse
aReference SBP

beference DBP. Comparisons of data among classes of SBP and DBP were performed by Kruskal-Wallis test with Bonferroni's correction. ${ }^{\#} P<0.20,{ }^{*} P<0.05$ and ${ }^{* *} P<0.01$. 


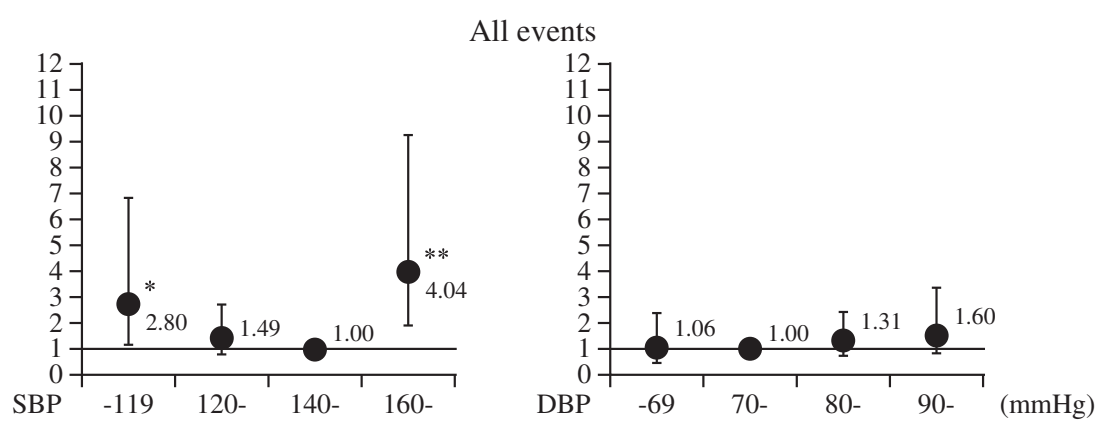

Disability
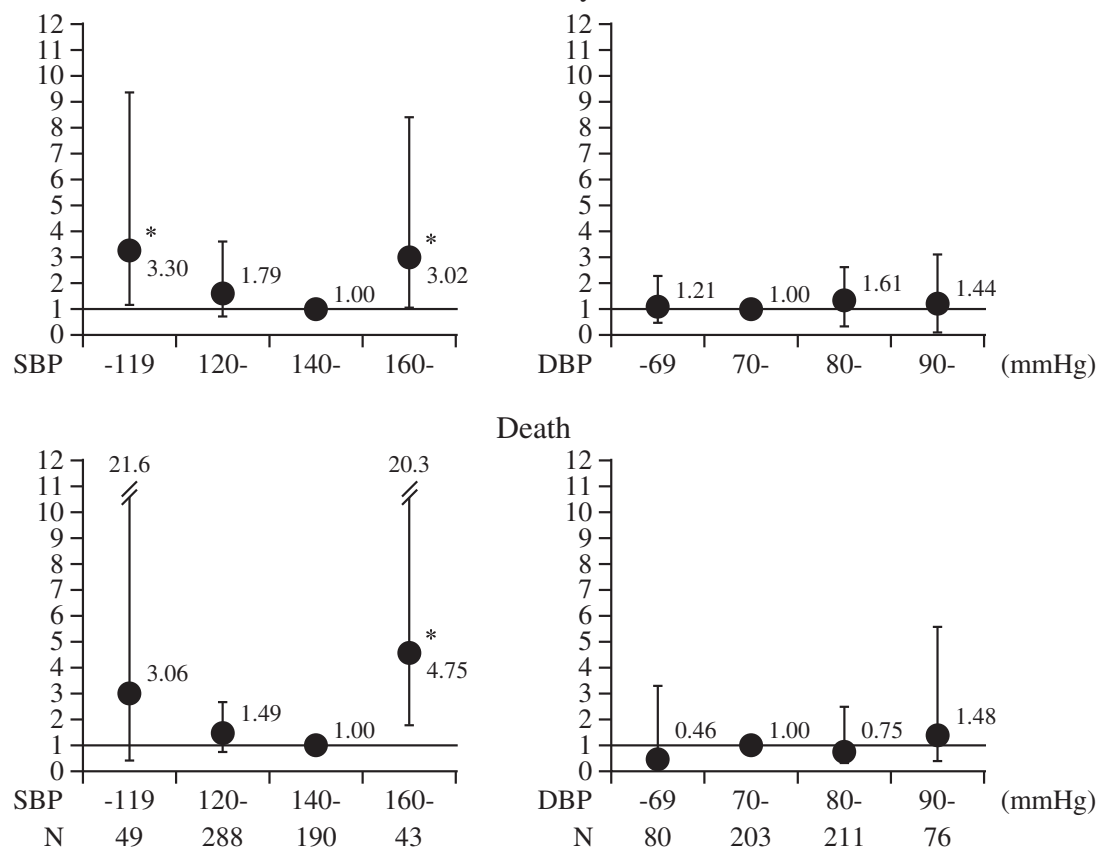

Death

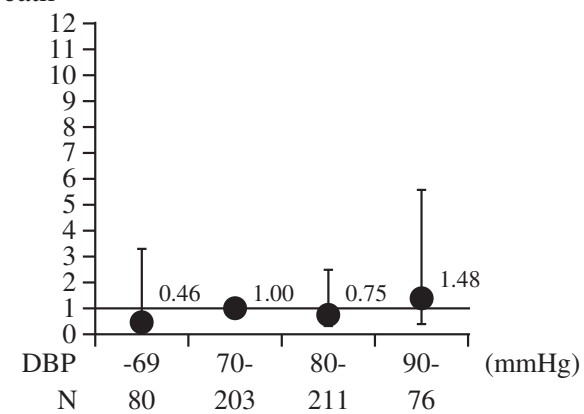

Figure 1 Relationship between baseline blood pressure (BP) and the hazard ratio of incident disability or death. Data are presented with relative risks and $95 \%$ confidence intervals with reference to patients with baseline systolic BP (SBP) of 140-159 mm Hg and patients with baseline diastolic BP (DBP) of 70-79 mm Hg. ${ }^{*} P<0.05 ;{ }^{*} P<0.01$.

\section{DISCUSSION}

The present study newly revealed an emerging profile of treated hypertension and the discontinuance of disability-free survival in community-dwelling elderly subjects. The advantages of the present study are as follows: Long-Term Care Insurance system certification is based on strictly established, uniform criteria throughout Japan, ${ }^{17,18}$ and the included information enabled a very high follow-up rate in the present study (98.4\%). Another advantage was that having information about the causal disease for incident disability enabled clarification of whether the risk of incident disability owing to particular causal diseases was higher in any of the SBP groups.

Practitioner's trial on the efficacy of antihypertensive treatment in elderly patients with hypertension II (PATE-Hypertension-II) ${ }^{9}$ and ONTARGET $^{10}$ revealed that elderly patients with higher achieved BP $(\geqslant 160 \mathrm{~mm} \mathrm{Hg})$ had significantly higher incidences of CV events. The present study revealed that patients with baseline $\mathrm{SBP} \geqslant 160 \mathrm{~mm} \mathrm{Hg}$ had a significantly higher risk not only of total death and also for incident disability, compared with the control group (Figure 1). We also observed an association of baseline SBP $\geqslant 160 \mathrm{~mm} \mathrm{Hg}$ with an increased risk of incident disability owing to falls/bone fractures (Figure 3). Although the precise reason for the association are not clear, one of the possible explanations is hypertension-induced development of white matter lesions, ${ }^{29}$ which increase the risk for incident bone fracture in community-dwelling elderly subjects. ${ }^{30}$ Moreover, a sub-analysis of Hypertension in the Very Elderly Trial revealed that sufficient reduction of BP in very old patients with SBP $\geqslant 160 \mathrm{~mm} \mathrm{Hg}$ was associated with a significant reduction in fracture rate. ${ }^{31}$ The precise mechanism for the association should be clarified in the future.

The present study clearly detected J-curve phenomena for the risk of incident disability or death, as well as for incident disability alone (Figure 1). The J-curve phenomenon appeared in patients aged $\geqslant 75$ years but not in younger patients (Figure 2). The SBP range at the HR nadir of 140-159 $\mathrm{mm} \mathrm{Hg}$ observed in the present study was somewhat higher than the target BP recommended for elderly patients aged $\geqslant 75$ years by the Japanese treatment guidelines for hypertension, which include both using an intermediate target $\mathrm{BP}$ of $<150 / 90 \mathrm{~mm} \mathrm{Hg}$ and attempting to lower the patient's BP to $<140 / 90 \mathrm{~mm} \mathrm{Hg}$ if possible. ${ }^{26}$ However, a lower target BP is not necessarily beneficial in elderly patients. $^{32}$ Indeed, in many large-scale clinical studies in elderly hypertensive patients aged $\geqslant 60$ years, the mean BP achieved by antihypertensive treatment was $141-152 / 77-85 \mathrm{~mm} \mathrm{Hg} .{ }^{2-8}$ Moreover, 
$<75$ years, $\mathrm{SBP}$

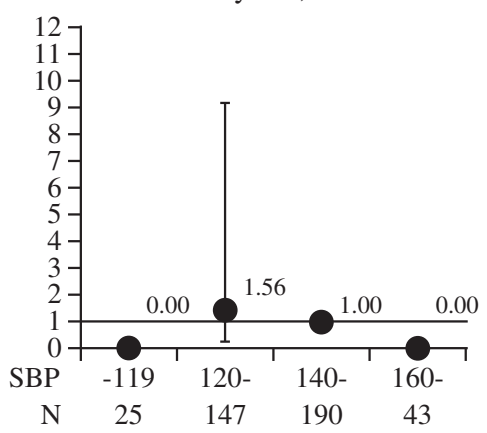

$\geq 75$ years, $\mathrm{SBP}$

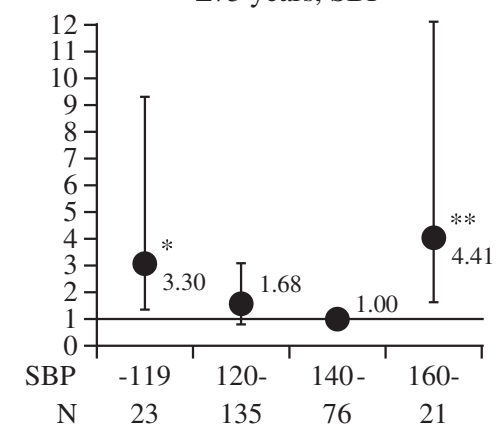

$<75$ years, DBP

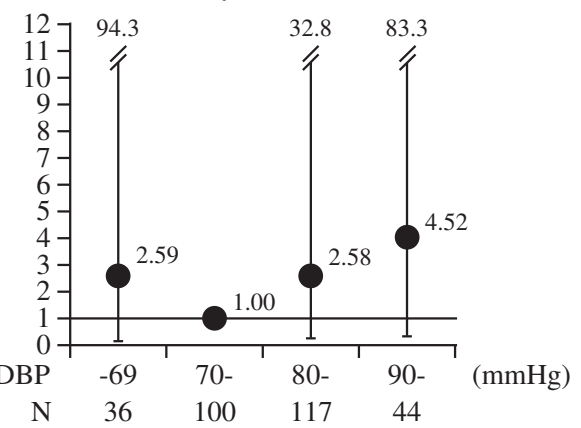

$\geq 75$ years, DBP

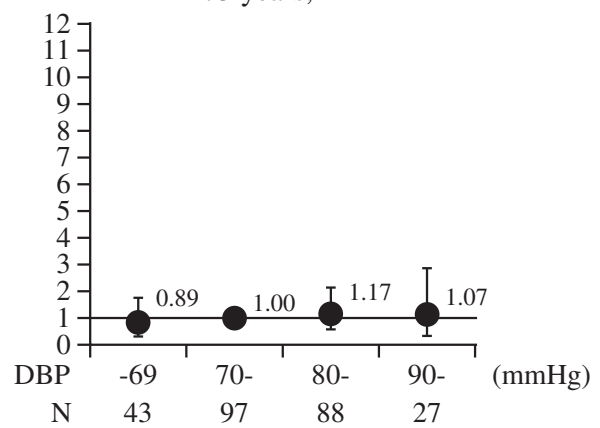

Figure 2 Relationship between baseline blood pressure (BP) and hazard ratio of incident disability or death in patients $<75$ years or $\geqslant 75$ years. Keys as in Figure 1.

Cerebral events

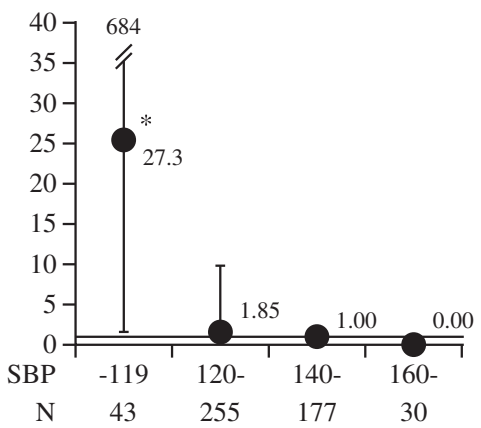

Dementia / Depression

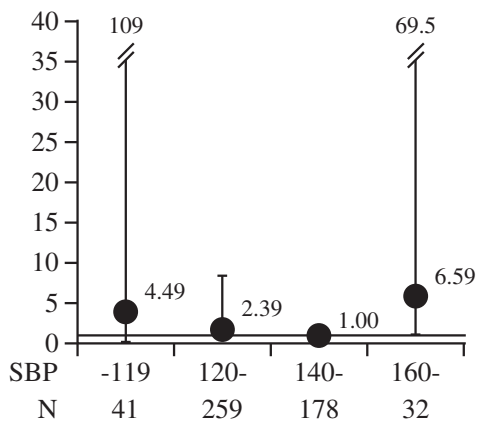

Falls / Fractures

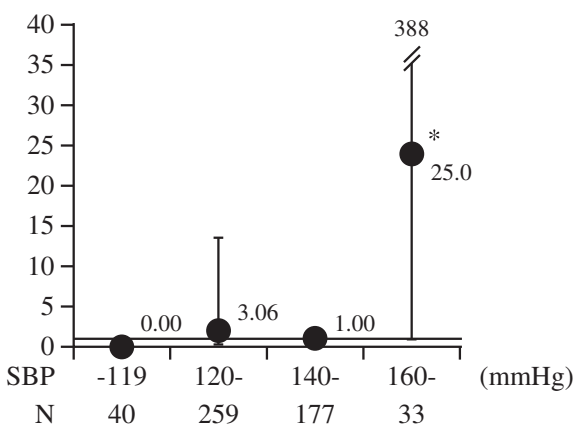

Others

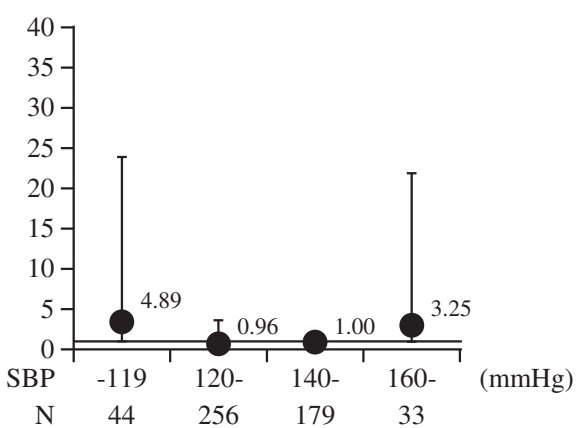

Figure 3 Relationship between baseline systolic blood pressure (SBP) and hazard ratio of incident disability according to the four categories of first causal disease for support/care need on doctor's assessment form. Keys as in Figure 1.

a sub-analysis of Systolic Hypertension in the Elderly Program (SHEP) (mean age 72 years) showed that participants whose in-trial SBP was lower than $160 \mathrm{~mm} \mathrm{Hg}$ or $150 \mathrm{~mm} \mathrm{Hg}$ experienced significant reductions in total stroke incidence compared with those with SBP higher than the respective thresholds, although the reduction of stroke incidence in those with $\mathrm{SBP}<140 \mathrm{~mm} \mathrm{Hg}$ was 
not significant compared with that in those with $\mathrm{SBP} \geqslant 140 \mathrm{~mm} \mathrm{Hg},{ }^{33}$ indicating that reduction of stroke incidence could be achieved most effectively in those with in-trial SBP of $140-159 \mathrm{~mm} \mathrm{Hg}$. Furthermore, among the Japanese elderly hypertensive patients ( $\geqslant 75$ years) in the Japanese Trial to Assess Optimal Systolic Blood Pressure in Elderly Hypertensive Patients (JATOS), which compared the two-year effects of strict treatment to maintain SBP less than $140 \mathrm{~mm} \mathrm{Hg}$ (group A) with those of mild treatment to maintain SBP between 140 and $160 \mathrm{~mm} \mathrm{Hg}$ (group B), group B had a lower incidence of CV events compared with group A, although the difference was not significant. ${ }^{34}$ In addition to these findings, elevated BP ( $\geqslant 140 \mathrm{~mm} \mathrm{Hg})$ is not necessarily associated with a decreased survival rate in frail elderly subjects because elevated BP was independently associated with a lower risk of death $(\mathrm{HR}, 0.38)$ in subjects who could not complete a walk test $(6 \mathrm{~m})$, but it was associated with greater risk of mortality compared with subjects without elevated BP (HR, 1.35) among faster walkers $\left(\geqslant 0.8 \mathrm{~m} \mathrm{~s}^{-1}\right) .{ }^{35}$ Because the mean age of patients certified with disability in the present study was 80.6 years (Table 1), all of these reports might be compatible to the present observation that patients with SBP of $140-159 \mathrm{~mm} \mathrm{Hg}$ experienced the lowest risk for events.

PATE-Hypertension ${ }^{3}$ and PATE-Hypertension II $^{9}$ demonstrated J-curve phenomena for CV morbidity/mortality in elderly patients $(\geqslant 75$ years) with a J-curve point for SBP of $<120 \mathrm{~mm} \mathrm{Hg}$, similar to that in the present study (Figures 1 and 2). A sub-analysis of ONTARGET also demonstrated a J-curve phenomenon for CV morbidity/mortality in high-risk patients with a mean age of 66 years, with a J-curve point for SBP of $<130 \mathrm{~mm} \mathrm{Hg} .{ }^{10}$ The Japanese Survey for Valsartan In Deployment (J-VALID) also demonstrated a significant systolic J-curve phenomenon, with a J-curve point for SBP of $<120 \mathrm{mmHg}$ in elderly patients ( $\geqslant 75$ years). ${ }^{11} \mathrm{~J}$-curve phenomena in these studies were observed for cardiac events but not for stroke. In contrast, a sub-analysis of the International Verapamil SR-Trandolapril Study (INVEST) in patients with hypertension and coronary heart disease also showed J-curve phenomena for the primary endpoint in older age groups $(70-<80$ years, $\geqslant 80$ years) with SBP and DBP at the HR nadirs of $140 \mathrm{~mm} \mathrm{Hg}$ and $70 \mathrm{~mm} \mathrm{Hg}$, respectively, for the oldest age group ( $\geqslant 80$ years). ${ }^{14}$ The primary endpoint of INVEST included not only all-cause death and nonfatal myocardial infarction but also nonfatal stroke. ${ }^{14}$ This result, as well as those of SHEP, ${ }^{33}$ are partly compatible with our study, in which a J-curve phenomenon was observed for incident disability at least partly owing to cerebral events (Figure 3). In contrast, another sub-analysis of SHEP ${ }^{12}$ and a sub-analysis of the Systolic Hypertension in Europe in patients with concomitant coronary heart disease ${ }^{13}$ also demonstrated J-curve phenomena for the relationship of achieved DBP with J-curve points of $<60 \mathrm{~mm} \mathrm{Hg}$ and $<70 \mathrm{~mm} \mathrm{Hg}$, respectively. However, there were no differences in HR among the baseline DBP classes in the present study. Nevertheless, the observations in these previous reports, as well as in the present study, indicate the importance of avoiding excessive $\mathrm{BP}$ reduction because low BP can often be related to the unexpected manifestation of a J-curve paradox in very elderly hypertensive subjects with underlying chronic debilitating illnesses. ${ }^{36}$ Indeed, higher incidences of $\mathrm{CV}$ events and risk factors for $\mathrm{CV}$ were observed in the groups with lower SBP or DBP in the present study (Table 2).

This study had several limitations. First, the analyses performed in the present study could not address the causality of excess BP reduction in the increased risk of disability. The patients with baseline $\mathrm{SBP}<120 \mathrm{~mm} \mathrm{Hg}$ might have originally been at high risk for frailty because SBP is known to decrease in years immediately before dementia onset in community-dwelling hypertensive elderly subjects. $^{37}$ The risk of excess BP reduction in very elderly hypertensive patients should be assessed in the future in randomized, controlled trials that compare disability-free survival between hypertensive very elderly patients whose SBP is controlled at higher levels than $120 \mathrm{~mm} \mathrm{Hg}$ and patients whose SBP is sustained at $<120 \mathrm{~mm} \mathrm{Hg}$. Second, in light of the single community model, care must be taken in interpreting the results of the present study, and further evaluation in multi-regional trials is needed. Third, stratified sampling of incident disability or death according to the kinds of antihypertensive drugs used, including renin-angiotensin blockers, is also needed in future studies because the renin-angiotensin system is thought to have a crucial role in aging and/or frailty. ${ }^{38}$ Finally, because of the small number of normotensives and untreated hypertensives in the present study, precise analysis was statistically limited in these groups and should be examined in the future.

In conclusion, the present study clearly identified J-curve phenomena for the risk of incident disability or death in community-dwelling very elderly patients ( $\geqslant 75$ years) receiving antihypertensive treatment, indicating that having a low target BP could cause exacerbation of frailty in elderly patients.

\section{CONFLICT OF INTEREST}

The authors declare no conflict of interest.

\section{ACKNOWLEDGEMENTS}

This work was supported by Research Funding for Longevity Sciences from the National Center for Geriatrics and Gerontology (NCGG) Japan, Comprehensive Research on Aging and Health, the Ministry of Health, Labor and Welfare, and grants from the Ministry of Education, Culture, Sports, Science and Technology of Japan.

1 Insua JT, Sacks HS, Lau TS, Lau J, Reitman D, Pagano D, Chalmers TC. Drug treatment of hypertension in the elderly: a meta-analysis. Ann Intern Med 1994; 121: 355-362.

2 National Intervention Cooperative Study in Elderly Hypertensives Study Group. Randomized double-blind comparison of a calcium antagonist and a diuretic in elderly hypertensives. Hypertension 1999; 34: 1129-1133.

3 Ogihara T. Practitioner's trial on the efficacy of antihypertensive treatment in the elderly hypertension (The PATE-Hypertension study) in Japan. Am J Hypertens 2000; 13: 461-467.

4 Lindholm LH, Hansson L, Ekbom T, Dahlof B, Lanke J, Linjer E, Schersten B, Wester PO, Hedner T, de Faire U. Comparison of antihypertensive treatments in preventing cardiovascular events in elderly diabetic patients: results from the Swedish Trial in Old Patients with Hypertension-2. STOP Hypertension-2 Study Group. J Hypertens 2000; 18: 1671-1675.

5 Wing LM, Reid CM, Ryan P, Beilin LJ, Brown MA, Jennings GL, Johnston Cl, McNeil JJ, Macdonald GJ, Marley JE, Morgan TO, West MJ. A comparison of outcomes with angiotensin-converting-enzyme inhibitors and diuretics for hypertension in the elderly. N Engl J Med 2003; 348: 583-592.

6 Lithell H, Hansson L, Skoog I, Elmfeldt D, Hofman A, Olofsson B, Trenkwalder P, Zanchetti A. The Study on Cognition and Prognosis in the Elderly (SCOPE): principal results of a randomized double-blind intervention trial. J Hypertens 2003; 21: 875-886.

7 Lithell H, Hansson L, Skoog I, Elmfeldt D, Hofman A, Olofsson B, Trenkwalder P, Zanchetti A. The Study on COgnition and Prognosis in the Elderly (SCOPE); outcomes in patients not receiving add-on therapy after randomization. J Hypertens 2004; 22: 1605-1612.

8 Beckett NS, Peters R, Fletcher AE, Staessen JA, Liu L, Dumitrascu D, Stoyanovsky V, Antikainen RL, Nikitin Y, Anderson C, Belhani A, Forette F, Rajkumar C, Thijs L, Banya $\mathrm{W}$, Bulpitt CJ. Treatment of hypertension in patients 80 years of age or older. N Engl J Med 2008; 358: 1887-1898.

9 Ogihara T, Matsuoka H, Rakugi H. Practitioner's trial on the efficacy of antihypertensive treatment in elderly patients with hypertension II (PATE-hypertension II study) in Japan. Geriatr Gerontol Int 2011: 11: 414-421.

10 Sleight P, Redon J, Verdecchia P, Mancia G, Gao P, Fagard R, Schumacher H, Weber M, Böhm M, Williams B, Pogue J, Koon T, Yusuf S. ONTARGET investigators. Prognostic value of blood pressure in patients with high vascular risk in the Ongoing Telmisartan Alone and in combination with Ramipril Global Endpoint Trial study. J Hypertens 2009; 27: 1360-1369. 
11 Yamazaki T, Kohro T, Chujo M, Ishigaki M, Hashimoto T. The occurrence rate of cerebrovascular and cardiac events in patients receiving antihypertensive therapy from the post-marketing surveillance data for valsartan in Japan (J-VALID). Hypertens Res 2013; 36: 140-150.

12 Somes GW, Pahor M, Shorr RI, Cushman WC, Applegate WB. The role of diastolic blood pressure when treating isolated systolic hypertension. Arch Intern Med 1999; 159: 2004-2009.

13 Fagard RH, Staessen JA, Thijs L, Celis H, Bulpitt CJ, de Leeuw PW, Leonetti G, Tuomilehto J, Yodfat Y. On-treatment diastolic blood pressure and prognosis in systolic hypertension. Arch Intern Med 2007; 167: 1884-1891.

14 Denardo SJ, Gong Y, Nichols WW, Messerli FH, Bavry AA, Cooper-Dehoff RM Handberg EM, Champion A, Pepine CJ. Blood pressure and outcomes in very old hypertensive coronary artery disease patients: an INVEST substudy. Am J Med 2010; 123: 719-726.

15 Wang L, van Belle G, Kukull WB, Larson EB. Predictors of functional change: A longitudinal study of nondemented people aged 65 and older. J Am Geriatr Soc 2002; 50: 1525-1534.

16 Bastos-Barbosa RG, Ferriolli E, Coelho EB, Moriguti JC, Nobre F, da Costa Lima NK. Association of frailty syndrome in the elderly with higher blood pressure and other cardiovascular risk factors. Am J Hypertens 2012; 25: 1156-1161.

17 Tsutsui T, Muramatsu N. Care-needs certification in the long-term care insurance system of Japan. J Am Geriatr Soc 2005; 53: 522-527.

18 Tsutsui T, Muramatsu N. Japan's universal long-term care system reform of 2005: costs and realizing a vision. J Am Geriatr Soc 2007; 55: 1458-1463.

19 Koizumi Y, Hamazaki Y, Okuro M, Iritani O, Yano H, Higashikawa T, Iwai K, Morimoto S. Association between hypertension status and the screening test for frailty in elderly community-dwelling Japanese. Hypertens Res 2013; 36: 639-644.

20 Saito I, Kokubo Y, Yamagishi K, Iso H, Inoue M, Tsugane S. Diabetes and the risk of coronary heart disease in the general Japanese population: the Japan Public Health Center-based prospective (JPHC) study. Atherosclerosis 2011; 216: 187-191

21 Matsuo S, Imai E, Horio M, Yasuda Y, Tomita K, Nitta K, Yamagata K, Tomino Y, Yokoyama $H$, Hishida $A$, on behalf of the collaborators developing the Japanese equation for estimated GFR. Revised equations for estimated GFR from serum creatinine in Japan. Am J Kidney Dis 2009; 53: 982-992.

22 Kuzuya T, Nakagawa S, Satoh J, Kanazawa Y, Iwamoto Y, Kobayashi M, Nanjo K, Sasaki A, Seino Y, Ito C, Shima K, Nonaka K, Kadowaki T. Committee of the Japan Diabetes Society on the diagnostic criteria of diabetes mellitus. Report of the Committee on the classification and diagnostic criteria of diabetes mellitus. Diabetes Res Clin Pract 2002; 55: 65-85.

23 Bando Y, Kanehara H, Aoki K, Katoh K, Toya D, Tanaka N. Characteristics of undiagnosed diabetes mellitus in a population undergoing health screening in Japan: target populations for efficient screening. Diabetes Res Clin Pract 2009; 83: 341-346.

24 Nagahama K, Inoue T, Iseki K, Touma T, Kinjo K, Ohya Y, Takishita S. Hyperuricemia as a predictor of hypertension in a screened cohort in Okinawa, Japan. Hypertens Res 2004; 27: 835-841.

25 Sullivan DH, Roberson PK, Bopp MM. Hypoalbuminemia 3 months after hospital discharge: significance for long-term survival. J Am Geriatr Soc 2005; 53 1222-1226.

26 Japanese Society of Hypertension Committee. The Japanese Society of Hypertension Guidelines for the Management of Hypertension (JSH 2009). Hypertens Res 2009; 32: 3-107.

27 Cox DR. Regression models and life tables. J R Statist Soc (B) 1972; 34: 187-220.

28 Concato J, Feinstein AR, Holford TR. The risk of determining risk with multivariable models. Ann Intern Med 1993; 118: 201-210.

29 Fukuda $\mathrm{H}$, Kitani M. Differences between treated and untreated hypertensive subjects in the extent of periventricular hyperintensities observed on brain MRI. Stroke 1995, 26: 1593-1597.

30 Corti MC, Baggio G, Sartori L, Barbato G, Manzato E, Musacchio E, Ferrucci L, Cardinali G, Donato D, Launer LJ, Zambon S, Crepaldi G, Guralnik JM. White matter lesions and the risk of incident hip fracture in older persons: results from the progetto veneto anziani study. Arch Intern Med 2007; 167: 1745-1751.

31 Peters R, Beckett N, Burch L, de Vernejoul MC, Liu L, Duggan J, Swift C, Gil-Extremera $B$, Fletcher A, Bulpitt C. The effect of treatment based on a diuretic (indapamide) +1 ACE inhibitor (perindopril) on fractures in the Hypertension in the Very Elderly Trial (HYVET). Age Ageing 2010; 39: 609-616.

32 August P. Initial treatment of hypertension. N Engl J Med 2003; 348: 610-616.

33 Perry HM Jr, Davis BR, Price TR, Applegate WB, Fields WS, Guralnik JM, Kuller L, Pressel S, Stamler J, Probstfield JL. Effect of treating isolated systolic hypertension on the risk of developing various types and subtypes of stroke: the Systolic Hypertension in the Elderly Program (SHEP). JAMA 2000; 284: 465-471.

34 JATOS Study Group. Principal results of the Japanese trial to assess optimal systolic blood pressure in elderly hypertensive patients (JATOS). Hypertens Res 2008; 31: 2115-2127.

35 Odden MC, Peralta CA, Haan MN, Covinsky KE. Rethinking the association of high blood pressure with mortality in elderly adults: the impact of frailty. Arch Intern Med 2012; 172: 1162-1168.

36 Angeli F, Reboldi G, Verdecchia P. Hypertension and the J-curve phenomenon: implications for tight blood pressure control. Hypertens Res 2013; 36: 109-111.

37 Skoog I, Lernfelt B, Landahl S, Palmertz B, Andreasson LA, Nilsson L, Persson G Odén A, Svanborg A. 15-year longitudinal study of blood pressure and dementia. Lancet 1996; 347: 1141-1145.

38 Abadir PM. The frail renin-angiotensin system. Clin Geriatr Med 2011; 27: 53-65. 